\title{
Estimation of the radionuclide inventory in LWR spent fuel assembly structural materials for long-term safety analysis
}

\author{
Stefano Caruso \\ Radioactive Materials Division, National Cooperative for the Disposal of Radioactive Waste (NAGRA), Hardstrasse 73, 5430 \\ Wettingen, Switzerland
}

Received: 25 September 2015 / Received in final form: 4 November 2015 / Accepted: 24 November 2015

Published online: 15 January 2016

\begin{abstract}
The radionuclide inventory of materials irradiated in a reactor depends on the initial material composition, irradiation history and on the magnitude and spectrum of the neutron flux. The material composition of a fuel assembly structure includes various alloys of Zircaloy, Inconel and stainless steel. The existing impurities in these materials are very important for accurate determination of the activation of all nuclides with a view to assessing the radiological consequences of their geological disposal. In fact, the safety assessments of geological repositories require the average and maximum (in the sense of very conservative) inventories of the very long-lived nuclides as input. The purpose of the present work is to describe the methodology applied for determining the activation of these nuclides in fuel assembly structural materials by means of coupled depletion/activation calculations and also to crosscheck the results obtained from two approaches. $\mathrm{UO}_{2}$ and MOX PWR fuels have been simulated using SCALE/TRITON, simultaneously irradiating the fuel region in POWER mode and the cladding region in FLUX mode and aiming to produce binary macro cross-section libraries by applying accurate local neutron spectra in the cladding region as a function of irradiation history that are suitable for activation calculations. The developed activation libraries have been re-employed in a second run using the ORIGEN-S program for a dedicated activation calculation. The axial variation of the neutron flux along the fuel assembly length has also been considered. The SCALE calculations were performed using a 238-group cross-section library, according to the ENDF/B-VII. The results obtained with the ORIGEN-S activation calculations are compared with the results obtained from TRITON via direct irradiation of the cladding, as allowed by the FLUX mode. It is shown that an agreement on the total calculated activities can be found within $55 \%$ for MOX and within $22 \%$ for $\mathrm{UO}_{2}$, whereas the latter is reduced to $9 \%$ when more accurate irradiation data are used (core-follow flux data instead of life-average flux data).
\end{abstract}

\section{Introduction}

In the context of characterizing spent fuel as technical waste $^{1}$, the assessment of the radionuclide inventory not limited to the fuel region but also including the cladding and structural materials is very important because of the build-up of very long-lived nuclides relevant for long-term safety analysis. Moreover, the release of these radionuclides from Zircaloy cladding and structural materials as a result of corrosion processes is much faster than the process of spent fuel dissolution. For this reason, these nuclides need to be treated separately.

\footnotetext{
* e-mail: stefano.caruso@nagra.ch

${ }^{1}$ In strict terms the spent fuel is not classified as a waste.
}

An accurate determination of the induced activity can be performed if the activation study relies on knowledge of the real fuel depletion characteristics, such as the neutron flux spectrum in the material investigated. The assessment of the nuclide inventory from the perspective of geological disposal has a double aspect, being related on the one hand to the fuel handling and encapsulation operations (short- to medium-lived nuclides are more relevant for the dose rate contribution) and, on the other hand, to the long-term safety aspects. In fact, the longlived nuclides, especially those producing the most decay heat, are relevant for the repository safety assessment. All this requires considerable effort in defining and validating a spent fuel depletion/activation methodology that can provide a radionuclide inventory with acceptable accuracy. 
In the present case, the significant heterogeneity of the fuel used in the five Swiss reactors makes this task highly complex. In this work, the SCALE/TRITON depletion sequence [1] and the stand-alone ORIGEN-S code [2] are both used to calculate the induced activity for high burnup fuels. The results obtained with TRITON first and then ORIGEN-S employing activation libraries built with TRITON itself are compared and discussed. Furthermore, several available methodologies are discussed for a more comprehensive but not exhaustive analysis of the topic.

Section 2 discusses the set of spent fuel assemblies to be characterized, including material components and impurities. Section 3 gives an overview of the methodologies used for the activation studies, describing in more detail the depletion/activation codes used and the criteria applied for accounting for the axial variations of the neutron flux. The results and conclusions are presented in Sections 4 and 5 respectively.

\section{Spent fuel characteristics}

\subsection{Representative fuel assembly data}

Basically, the assessment of the radiological inventory assumes as a basis the spent nuclear fuel (SNF) that has not been sent for reprocessing and is foreseen for geological disposal. From the available database, and also based on predictions, several SNF categories were generated within the framework of a NAGRA model inventory to be used for long-term safety assessment [3]. An overview of the implemented SNF categories is given in Table 1, according

Table 1. FA (fuel assembly) categorization per NPP, fuel type, average initial enrichment and average burnup to be considered for the repository.

\begin{tabular}{|c|c|c|c|c|}
\hline AGT-ISRAM & Owner & Type & $\begin{array}{l}{ }^{235} \mathrm{U} / \mathrm{Pu} \\
\text { [wt.\%] }\end{array}$ & $\begin{array}{l}\mathrm{BU} \\
{\left[\mathrm{Gwd} / \mathrm{t}_{\mathrm{HM}}\right]}\end{array}$ \\
\hline J-B-950001 & KKB & $\mathrm{PWR} / \mathrm{UO}_{2}$ & 3.36 & 35.9 \\
\hline J-B-950002 & KKB & $\mathrm{PWR} / \mathrm{UO}_{2}$ & 3.71 & 43.5 \\
\hline J-B-950003 & KKB & $\mathrm{PWR} / \mathrm{UO}_{2}$ & 4.54 & 52.4 \\
\hline J-B-950004 & KKB & $\mathrm{PWR} / \mathrm{UO}_{2}$ & 4.5 & 55 \\
\hline J-B-950005 & KKB & $\mathrm{PWR} / \mathrm{UO}_{2}$ & 4.5 & 38.3 \\
\hline J-B-950501 & KKB & PWR / MOX & $0.71 / 2.73$ & 33.8 \\
\hline J-B-950502 & KKB & PWR / MOX & $0.26 / 3.66$ & 36.4 \\
\hline J-B-950503 & KKB & PWR / MOX & $0.26 / 3.69$ & 43 \\
\hline J-B-950504 & KKB & PWR / MOX & $0.27 / 4.81$ & 53.9 \\
\hline J-B-950505 & KKB & PWR / MOX & $0.27 / 4.86$ & 55 \\
\hline J-G-950001 & KKG & $\mathrm{PWR} / \mathrm{UO}_{2}$ & 3.5 & 39.3 \\
\hline J-G-950002 & KKG & $\mathrm{PWR} / \mathrm{UO}_{2}$ & 3.46 & 47 \\
\hline J-G-950003 & KKG & $\mathrm{PWR} / \mathrm{UO}_{2}$ & 4.39 & 56.6 \\
\hline J-G-950004 & KKG & $\mathrm{PWR} / \mathrm{UO}_{2}$ & 4.4 & 55 \\
\hline J-G-950005 & KKG & $\mathrm{PWR} / \mathrm{UO}_{2}$ & 4.4 & 32.9 \\
\hline J-G-950501 & $\mathrm{KKG}$ & PWR / MOX & $0.26 / 4.78$ & 54.8 \\
\hline J-G-950502 & KKG & PWR / MOX & $0.25 / 4.78$ & 55 \\
\hline J-L-950001 & KKL & $\mathrm{BWR} / \mathrm{UO}_{2}$ & 1.67 & 18.3 \\
\hline J-L-950002 & KKL & $\mathrm{BWR} / \mathrm{UO}_{2}$ & 2.36 & 26.3 \\
\hline J-L-950003 & KKL & $\mathrm{BWR} / \mathrm{UO}_{2}$ & 2.71 & 34.5 \\
\hline J-L-950004 & KKL & $\mathrm{BWR} / \mathrm{UO}_{2}$ & 3.31 & 43.9 \\
\hline J-L-950005 & KKL & $\mathrm{BWR} / \mathrm{UO}_{2}$ & 4.01 & 50.6 \\
\hline J-L-950006 & KKL & $\mathrm{BWR} / \mathrm{UO}_{2}$ & 4.3 & 55 \\
\hline J-L-950007 & KKL & $\mathrm{BWR} / \mathrm{UO}_{2}$ & 4 & 32 \\
\hline J-M-95-0001 & KKM & $\mathrm{BWR} / \mathrm{UO}_{2}$ & 3.13 & 40.3 \\
\hline J-M-95-0002 & KKM & $\mathrm{BWR} / \mathrm{UO}_{2}$ & 3.67 & 48.5 \\
\hline J-M-95-0003 & KKM & $\mathrm{BWR} / \mathrm{UO}_{2}$ & 4.08 & 52.1 \\
\hline J-M-95-0004 & KKM & $\mathrm{BWR} / \mathrm{UO}_{2}$ & 4.2 & 55 \\
\hline J-M-95-0006 & KKM & $\mathrm{BWR} / \mathrm{UO}_{2}$ & 4.2 & 30.3 \\
\hline
\end{tabular}


Table 2. Impurities assumed to be present $(<1000 \mathrm{ppm})$ in the FA structural material (in ppm) for the activation calculations $[4,5]$.

\begin{tabular}{lccccccccccccccc}
\hline & $\mathrm{Al}$ & $\mathrm{B}$ & $\mathrm{C}$ & $\mathrm{Ca}$ & $\mathrm{Cd}$ & $\mathrm{Cl}$ & $\mathrm{Co}$ & $\mathrm{Cr}$ & $\mathrm{Cu}$ & $\mathrm{Fe}$ & $\mathrm{H}$ & $\mathrm{Hf}$ & $\mathrm{Mg}$ & $\mathrm{Mn}$ & $\mathrm{Mo}$ \\
\hline Zry-4 & 75 & 0.5 & 270 & 30 & 0.5 & 20 & 1.5 & $>$ & 50 & $>$ & 25 & 100 & 20 & 50 & 50 \\
Steel & 0 & 0 & 800 & 0 & 0 & 0 & 500 & $>$ & 0 & $>$ & 0 & 0 & 0 & $>$ & 0 \\
\hline & $\mathrm{N}$ & $\mathrm{Na}$ & $\mathrm{Nb}$ & $\mathrm{Ni}$ & $\mathrm{O}$ & $\mathrm{P}$ & $\mathrm{Pb}$ & $\mathrm{Si}$ & $\mathrm{Sn}$ & $\mathrm{Th}$ & $\mathrm{Ti}$ & $\mathrm{U}$ & $\mathrm{W}$ & $\mathrm{Zr}$ & \\
\hline Zry-4 & 80 & 20 & 100 & 700 & $>$ & 30 & 130 & 120 & $>$ & 0.5 & 50 & 1.5 & 100 & $>$ \\
Steel & 400 & 0 & 0 & $>$ & 0 & 450 & 0 & $>$ & 0 & 0.05 & $>$ & 0.05 & 0 & 0 \\
\hline
\end{tabular}

to $\mathrm{AGT}^{2}$-ISRAM ${ }^{3}$ [4] denomination, the $\mathrm{NPP}^{4}$, the type of fuel, the average enrichment and burnup. Each one of the 29 categories illustrated in the table will be characterized using the methodology described in this paper. However, the present study is limited to the fuel from the Gösgen NPP, namely the $\mathrm{UO}_{2} \mathrm{~J}-\mathrm{G}-950004$ and MOX J-G-950502, both with a representative burnup of $55 \mathrm{GWd} / \mathrm{t}$.

\subsection{Structural materials and impurities}

For the calculation of the induced activity in structural material from irradiated fuel bundles, it is necessary to know exactly the material composition up to the impurities level. For this study, a typical Siemens FA, with $15 \times 15$ array, was considered as the reference. The impurity vectors of all the materials involved (e.g. Zircaloy-4, Inconel, steel) were used for the calculation. Table 2 shows the impurities assumed in the Zircaloy and steel, which correspond to the values used in the NAGRA Entsorgungsnachweis ${ }^{5}$ project $[5,6]$. The content of thorium, uranium and cobalt has recently been reviewed on the basis of sample measurements and is reported here. For illustration purposes, the table is limited to an impurities content of less than $1000 \mathrm{ppm}$.

\section{Analysis of LWR fuel assemblies}

The accuracy of activation calculations is determined largely by the accuracy and the completeness of the nuclear data associated with the transmutation process (macro cross-section libraries) and decay equations (nuclear data). These are the basic criteria to be used for the qualification of the method.

The methods employed for this activation study are described and discussed in the following sub-sections.

\footnotetext{
$\overline{{ }^{2} \text { AGT: waste package type. }}$

"Information System for Radioactive Materials (ISRAM)" for the long-term documentation of radioactive wastes and materials in Switzerland [4].

${ }^{4}$ KKB: Beznau; KKG: Gösgen; KKL: Leibstadt; KKM: Mühleberg.

${ }^{5}$ Demonstration of disposal feasibility for spent fuel, vitrified highlevel waste and long-lived intermediate-level waste.
}

\subsection{Methodologies}

Several approaches can be used for the assessment of the induced activation in the FA structure. A set of these, mainly based on the SCALE computer code system (SCALE 6.1) that is developed and maintained at ORNL, has been considered in this work and are highlighted here:

- integrated depletion/activation calculation at FA level, using the SCALE/TRITON sequence (fuel depletion by POWER mode and cladding/structure activation by FLUX mode);

- stand-alone ORIGEN-S activation calculation using a self-developed TRITON cladding library (already achieved in point 1 );

- development of a neutron activation cross-section library from a defined neutron flux spectrum in cladding/ structure (if known) using COUPLE [1] and interfacing the created activation library with ORIGEN-S for the radionuclide activity calculation;

- stand-alone ORIGEN-S activation calculation on the basis of an ORIGEN-ARP standard fuel library (inaccuracy in the neutron flux spectrum).

The first three methods can be considered as the most accurate, since getting the correct neutron spectrum for the cladding and the best cross-sections and decay data available. In particular, the first two are discussed in detail in the following sections. The results for methods 1 and 2 are presented later in Section 4. Methods 3 to 5 are, however, briefly discussed here.

Method 3 is based on the a priori knowledge of the neutron flux spectra in the cladding/structural materials. The spectrum can be calculated by means of dedicated neutron transport calculations, e.g. by employing MCNP [7] to model the reactor core and running the simulation in criticality mode and extracting a representative neutron flux spectrum ${ }^{6}$ for the cladding regions. The spectrum can be successively given to COUPLE, which creates binary nuclear data libraries (infinite dilution cross-sections) to be used directly in the depletion code ORIGEN-S for the activation calculations. Method 4 is a less accurate approach consisting of running ORIGEN-S coupled with the ORIGEN-ARP standard fuel libraries. The neutron flux spectrum used is the one in fuel, which is harder than

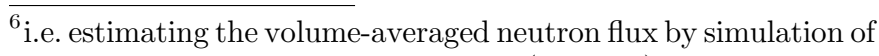
particle scoring in "cladding" detector (F4 tally). 
the characteristic spectrum in cladding. This introduces a larger uncertainty in the estimation of the inventory. Furthermore, not all ARP libraries are updated with the most recent cross-section libraries. However, this approach has the advantage of being less time-consuming.

It may be worth mentioning other activation codes that can be employed for this analysis. Some of these codes are listed here, with related cross-section databases: FISPACT2007 [8] with EAF-2007 and the decay data on JEFF3.1, CINDER'90 [9] with ENDF/B-VI and EAF-3 and GRSAKTIV-II [10] with 84-group HAMMER data. The evaluation of these codes is, however, outside the scope of this paper.

\subsection{Depletion calculations and neutron activation cross-section libraries}

As introduced previously, two methods were employed for this activation study, both based on the SCALE package. The first approach (see point 1 in Sect. 3.1) is an integrated depletion/activation calculation at FA level, based entirely on the TRITON sequence. The second method is based on decoupling the TRITON sequence in a 2-step calculation, where the cladding macro cross-section libraries are first developed by TRITON and later used by ORIGEN-S stand-alone. Because TRITON is at the base of both methodologies, this section is devoted to describing the TRITON depletion model.

The TRITON depletion sequence allows transport and depletion calculations to be performed at fuel assembly level. TRITON consists of a sequence of different modules which are sequential-coupling transport calculations with depletion calculations. The resonance self-shielding is performed using CENTRM to prepare problem-dependent pointwise continuous-energy flux for use in the NEWT multigroup transport solver. CENTRM computes "continuous-energy" neutron spectra using discrete ordinance or other deterministic approximations for the Boltzmann transport equation. TRITON uses the BONAMI module for the unresolved-resonance energy region, performing Bondarenko calculations for the resonance self-shielding correction. Among several processing options, the CENTRM/PCM cross-section processing methodology was applied for the present study, because it is coupled with the most recent neutron libraries (ENDF/B-VII) and also because it can handle heterogeneous structures. The TDEPL calculation sequence was selected and the fuel region was depleted in POWER mode and the cladding region in FLUX mode.

As shown in Section 2, PWR $\mathrm{UO}_{2}$ and MOX $15 \times 15$ bundles, the type irradiated in the Gösgen (KKG) nuclear power plant, were considered. The $\mathrm{UO}_{2} \mathrm{FA}$ had an initial enrichment of $4.4 \mathrm{wt} . \%{ }^{235} \mathrm{U}$. The MOX fuel is characterized by a 3-region enrichment (high, medium and low $\mathrm{Pu}$ content), giving 0.25 wt. $\%$ of ${ }^{235} \mathrm{U}$ and 4.78 wt. $\%$ of fissile $\mathrm{Pu}$.

The main fuel characteristics, such as geometry, materials and other reactor-related parameters, were implemented. The control rods have been considered as fully extracted, this being their normal condition for most of their life in the reactor, meaning that the guide tubes are filled with water. Physical boundaries are set to mirror boundaries. The fuel was depleted using core-follow data, based on detailed irradiation history, for a final burnup of $55 \mathrm{GWd} / \mathrm{t}$ in both cases. A cross-section of the south-west $1 / 4 \mathrm{FA}$, as modeled with TRITON, is presented in Figure 1, where the $\mathrm{UO}_{2}$ is illustrated on the left and MOX on the right. A $4 \times 4$ unit cell coarse mesh structure was used.

Although a $1 / 8$ symmetry is given (in Fig. 1 , the rods with the same $1 / 8$ symmetry are illustrated with the same (a)

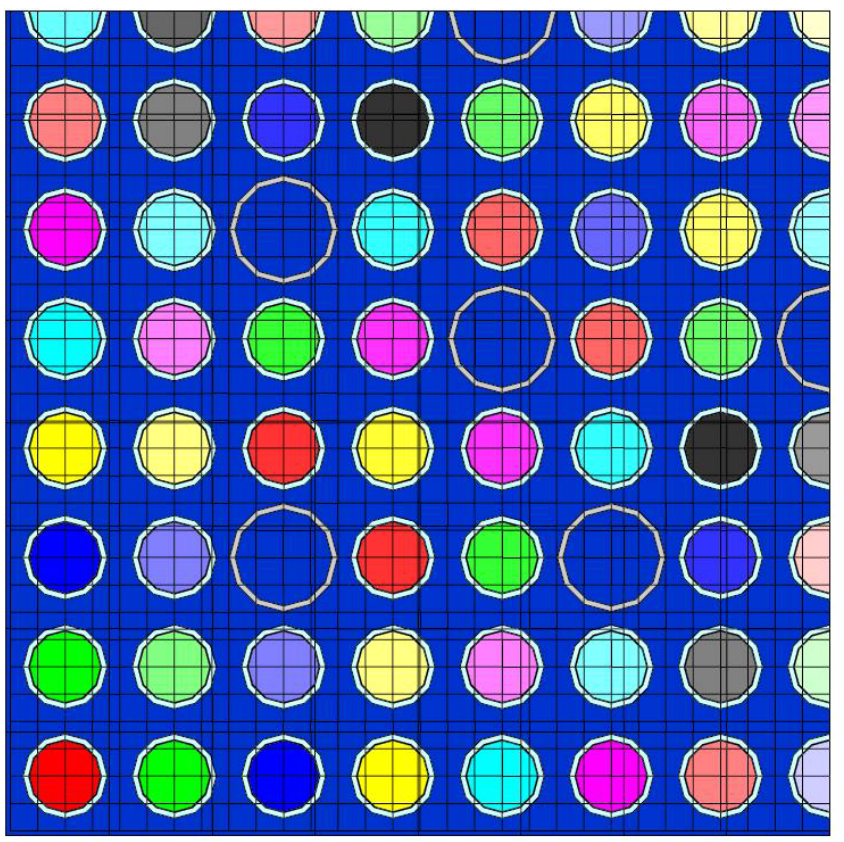

(b)

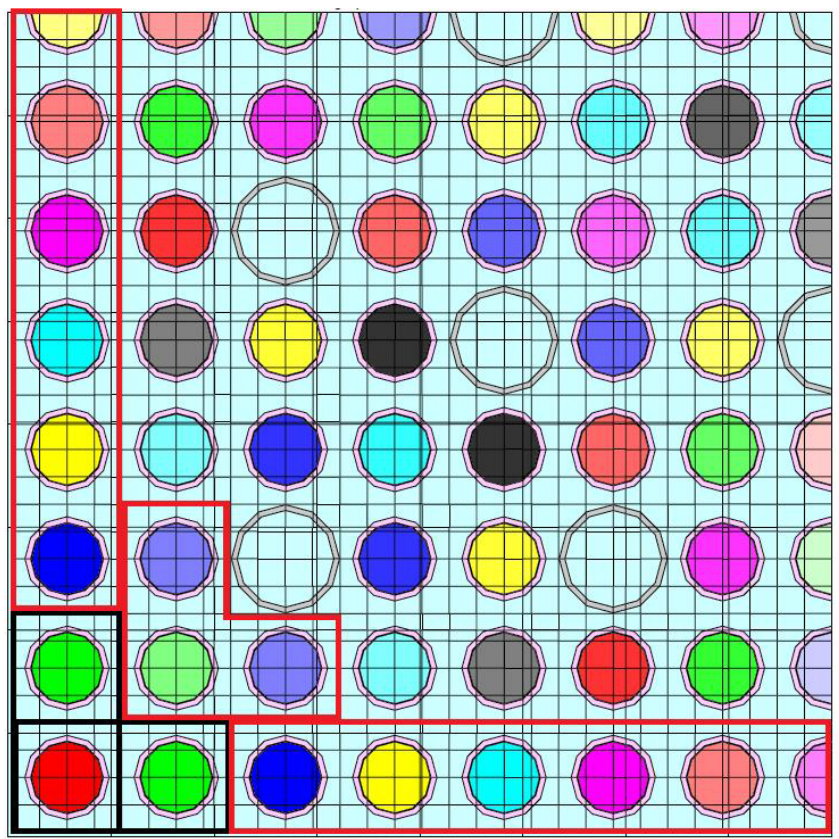

Fig. 1. $\mathrm{UO}_{2}$ (left) and MOX (right) KKG $1 / 4$ assembly fuel model in TRITON. 
color), the model of the FA was represented by $1 / 4 \mathrm{FA}$, using mirror boundary conditions. The effect of this model simplification is a reduction of computation time without a significant loss of accuracy.

The assign function, which simplifies the cross-section processing by calculating a particular rod and assigning this one to all other rods, was used for both $\mathrm{UO}_{2}$ and MOX models. However, because of the 3-region enrichment characterizing the plutonium rods in the MOX case, three different regions were assigned. These regions are defined as low $\mathrm{Pu}$-content fuel (black framed area on Fig. 1 right), medium $\mathrm{Pu}$-content fuel (red framed areas on Fig. 1) and high $\mathrm{Pu}$-content fuel (no framed areas).

TRITON provides the possibility to develop a problemspecific fuel model and, based on the model developed, to create a problem-dependent library. The neutron activation cross-section libraries for the cladding can be produced in the course of a TRITON depletion calculation. In fact, the depletion module allows a simultaneous run in POWER mode for the fuel region and in FLUX mode for the cladding region. The new binary cross-section libraries are produced for each region declared in the depletion module. In this work, the cladding was defined as a unique region and was irradiated according to the neutron flux spectrum calculated in the Zircaloy. The activation library produced in this way is customized only on the neutron spectrum in cladding and is based on the cross-section data ENDF/B-VII, with 238 neutron energy groups.

The multigroup cross-sections are then combined with the neutron flux solution and collapsed using the COUPLE code to create effective one-group cross-sections for use with ORIGEN. Burnup-dependent cross-section libraries for ORIGEN are saved during the TRITON depletion calculation at each depletion step. These libraries are created for each depleted mixture in the analyzed configuration.

\subsection{Implementing the activation libraries in ORIGEN-S}

The ORIGEN-S code is designed to function as a module of the SCALE code system and obtains problem-specific neutronic data through interaction with other modules of the system, such as the above-mentioned TRITON. ORIGEN-S data libraries can be generated by the TRITON sequence and, with these, ORIGEN-S can be run in a standalone configuration. In fact, time-dependent material concentrations are solved using the ORIGEN-S isotope depletion and decay code. For activation studies, the accuracy of the results depends on having an appropriately weighted cross-section library that is representative of the material being irradiated: flux-weighted cross-sections updated from the standard cross-section data on the basis of the real structure of a fuel assembly (FA typedependent). Moreover, the exact quantification of the impurities is fundamental, being through these isotopes that significant transmutation reactions are taking place; e.g. ${ }^{14} \mathrm{C}$ is produced by $(n, p)$ reactions on ${ }^{14} \mathrm{~N},{ }^{36} \mathrm{Cl}$ as result of $(n, \gamma)$ reactions on ${ }^{35} \mathrm{Cl}$, and ${ }^{60} \mathrm{Co},{ }^{94} \mathrm{Nb}$ also produced by $(n, \gamma)$ reactions on their stable isotopes. To these, other isotopes abundantly present into the structural materials and having remarkable resonances self-shielding properties are contributing to the global activation (see $(n, \gamma)$ reactions of ${ }^{55} \mathrm{Fe},{ }^{93} \mathrm{Zr}$ and ${ }^{63} \mathrm{Ni}$ ). With this approach, any material can be analyzed under specific spectral irradiation conditions. It is worth noting that ORIGEN-S is able to utilize multi-energy-group neutron flux and cross-sections in any group structure. However, the 238 multigroup space and energy cross-sections need to be collapsed in a spectrum-averaged (one-group) cross-section in order to solve the activation equation.

In order to employ ORIGEN-S stand-alone, the total neutron flux intensity must be given in the input as a function of irradiation time. The values for total flux can be extracted accordingly from the TRITON output, which gives values for any defined material region (e.g. fuel, cladding). Here, the average values $5.04 \times 10^{14} \mathrm{n} / \mathrm{cm}^{2} \mathrm{~s}$ for $\mathrm{UO}_{2}$ and $5.55 \times 10^{14} \mathrm{n} / \mathrm{cm}^{2} \mathrm{~s}$ for MOX were used respectively.

\subsection{Multi-region flux activation calculations}

A significant limitation of the current approach is the assumption of a two-dimensional model, which ignores the very important disuniformity of the axial neutron flux. The cladding in the extremities and the structural materials of the top and bottom of the FA are irradiated with a lower neutron flux than in the central position. As a consequence, the use of a constant axial flux introduces unacceptable inaccuracy. To overcome this, a neutron flux regiondependent factor was implemented. The factor was used to normalize the mass of material to the corresponding neutron flux for a specific region. The FA is divided into four main regions, each one characterized by an average representative neutron flux (see Tab. 3) coming from the determined extrapolation distance of the neutron flux along the full axial length of the core (see also Ref. [11]). The scaling factors are directly employed as a mass weighting factor for each material region of the FA, so that the mass of the material is normalized to the neutron flux. The employment of these weighting factors on the irradiated mass is equivalent to the application of a reduction factor on the neutron flux itself. This approach has the advantage of performing the simulation in one single run.

\section{Results and comparison}

The results of fuel activation calculations for the modeled fuel assemblies described above are given in Table 4, as

Table 3. Neutron flux regions in FA [11].

\begin{tabular}{ll}
\hline Reactor type & PWR \\
\hline Fuel type & Westinghouse \\
\hline Region of FA & Flux scaling factor \\
\hline Top end fitting & $10 \%$ \\
Gas plenum & $20 \%$ \\
Fueled region & $100 \%$ \\
Bottom end fitting & $20 \%$ \\
\hline
\end{tabular}




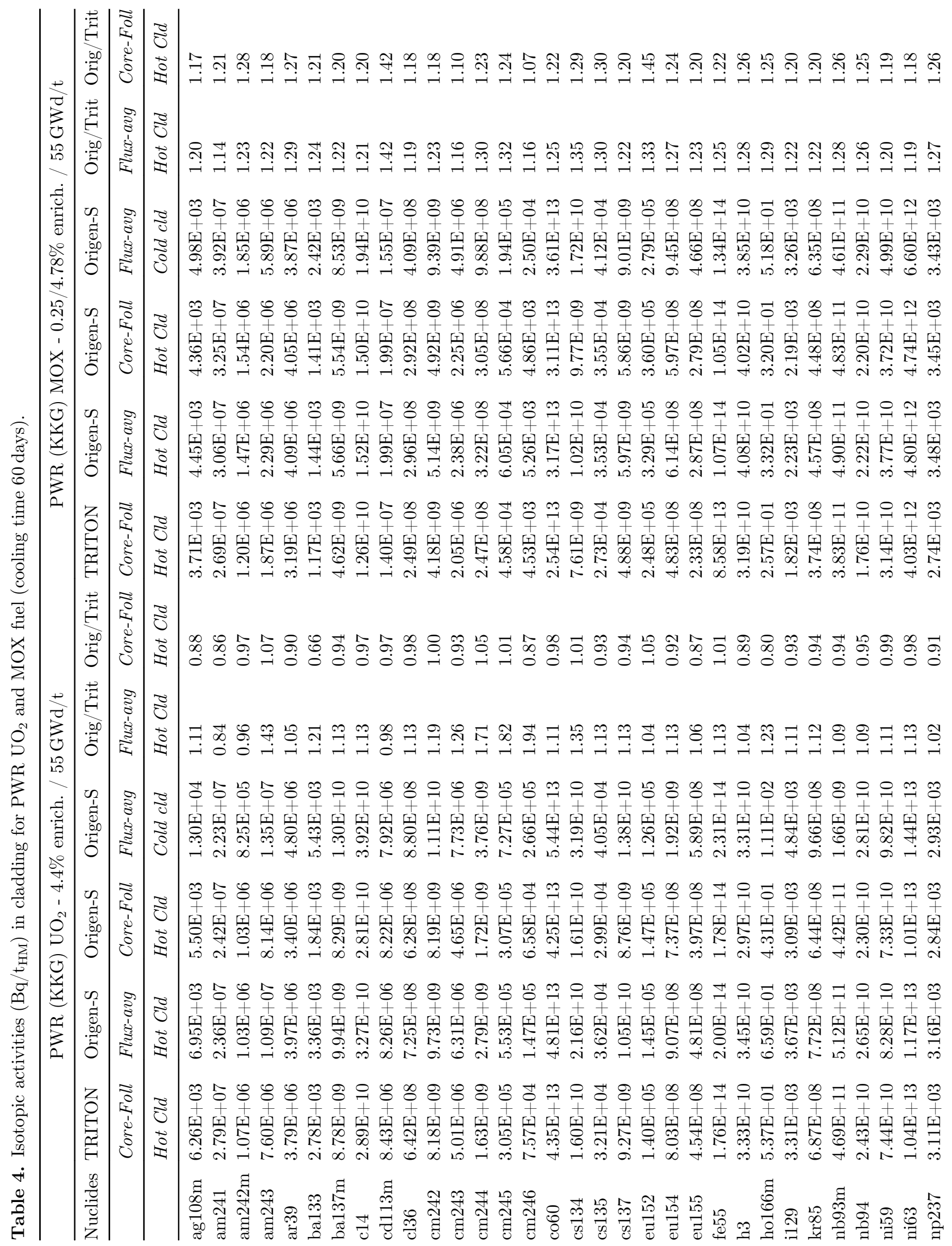




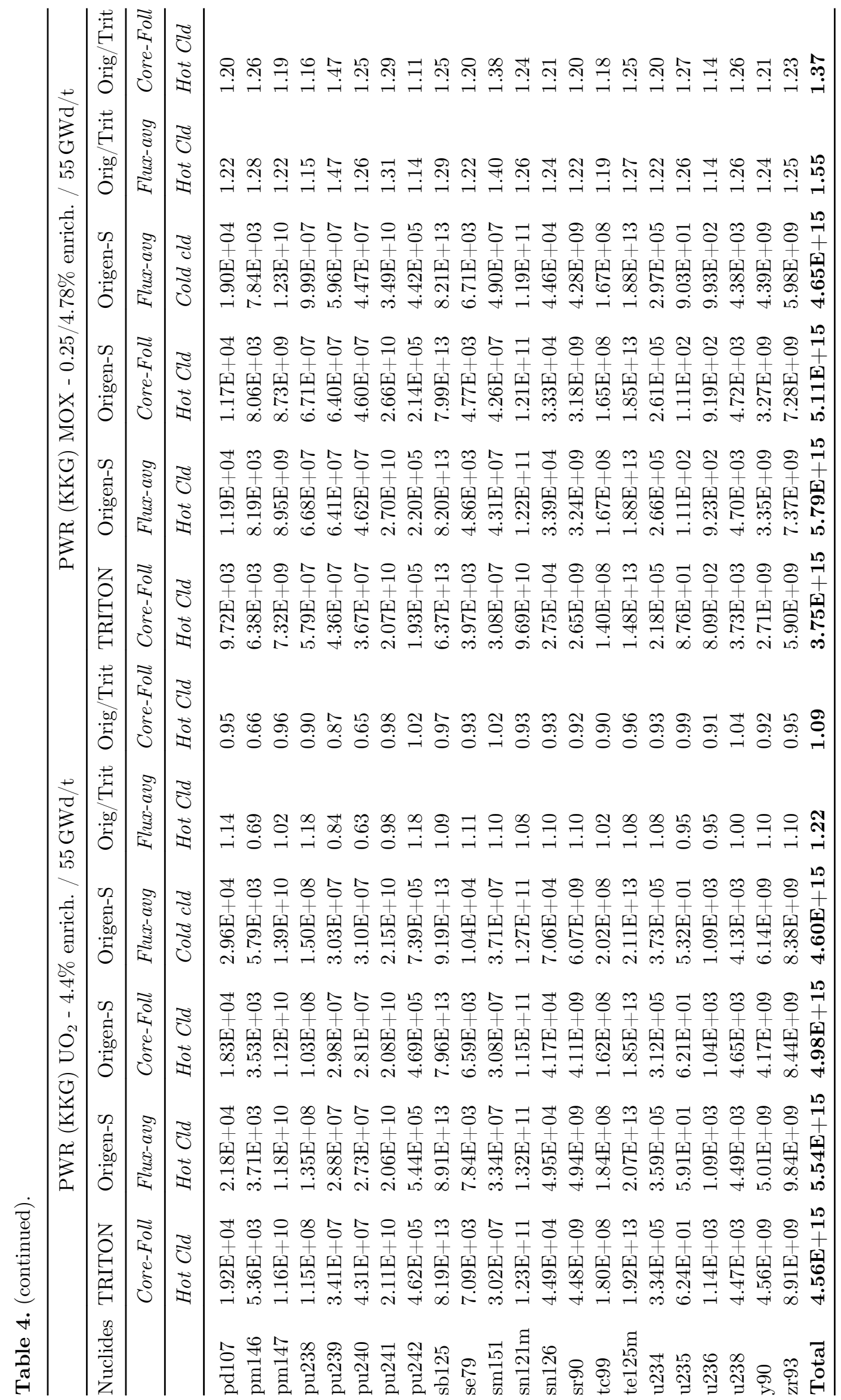




\section{UO2 PWR, 4.4 \% enrich., 55 GWd/t burnup}

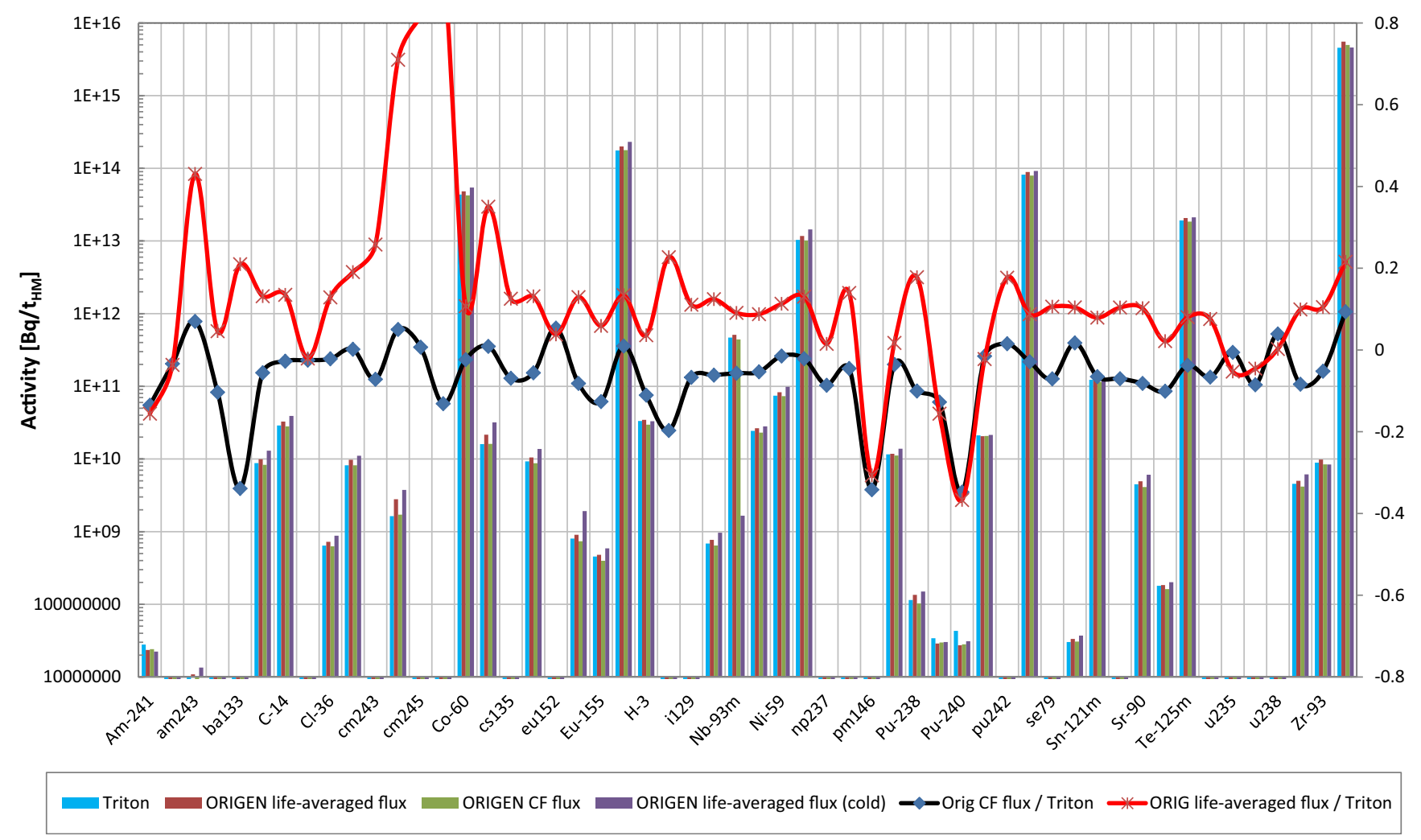

Fig. 2. Specific activities and deviations between TRITON and ORIGEN-S for the $\mathrm{UO}_{2} \mathrm{PWR}^{\mathrm{P}}$ case (4.4\% enrichment, burnup $=55 \mathrm{GWd} / \mathrm{t}, \mathrm{CT}=60$ days $)$.

specific activity $\left(\mathrm{Bq} / \mathrm{t}_{\mathrm{HM}}\right)$ normalized to 1 ton of heavy metal, for the cases of KKG $\mathrm{UO}_{2}$ and MOX PWR with $55 \mathrm{GWd} / \mathrm{t}$ burnup. Furthermore, the results are given for cladding in fuel rods (TRITON macro cross-section libraries for hot cladding) as well as for water rod cladding (TRITON macro cross-section libraries for cold cladding), aiming to show the influence of different spectral irradiation conditions on the final results. The calculations with ORIGEN-S were carried out using first a life-averaged flux value and then quasi-core-follow flux values (respectively Flux-avg and Core-Foll in Tab. 4). The calculation produced results for 328 nuclides $^{7}$, including activation products, fission products and actinides. However, Table 4 reports only a restricted set of nuclides relevant for longterm safety analysis. All values refer to a cooling time of 60 days, chosen to filter out the very short-lived isotopes.

The TRITON values in the table refer to the fuel rod cladding and are calculated using core-follow irradiation data. These results are compared against:

- the activities calculated for the hot cladding with ORIGEN-S using a life-averaged flux value (same time mesh as the following point);

\footnotetext{
${ }^{7}$ The set of 328 nuclides includes all relevant nuclides needed for long-term safety assessment, starting at time of emplacement into the geological disposal.
}

- the activities calculated for hot cladding, but employing core-follow flux data;

- the activities calculated for the cold cladding, based on life-averaged flux.

The following observations are derived from this study:

- a tendency to overpredict the activity in the ORIGEN-S calculation, more pronounced for the MOX case. This can be attributed to the approximation of the irradiation data used for ORIGEN-S calculations;

- in fact, the ORIGEN-S core-follow calculation agrees much better with the TRITON one $\left(9 \%\right.$ for $\mathrm{UO}_{2}$ and $37 \%$ for MOX) than the ORIGEN-S life-averaged one ( $22 \%$ for $\mathrm{UO}_{2}$ and $55 \%$ for MOX);

- there are isotopes that are very sensitive to irradiation history (e.g. ${ }^{246} \mathrm{Cm}$ activity for the $\mathrm{UO}_{2}$ fuel which shows a factor 1.94). The build-up of curium, in fact, involves a sequence of neutron captures. Thus, uncertainties in the determination of this element build-up as a result of uncertainties propagation of its precursors;

- around 20\% higher global activity between the ORIGEN calculation based on the hot cladding (fuel rod) library and the cold cladding (water rod) library, using the same irradiation conditions.

It is worth mentioning that the total activity given in the last row of the table refers to the full set of nuclides generated. Furthermore, the decay time windows due to outage were 


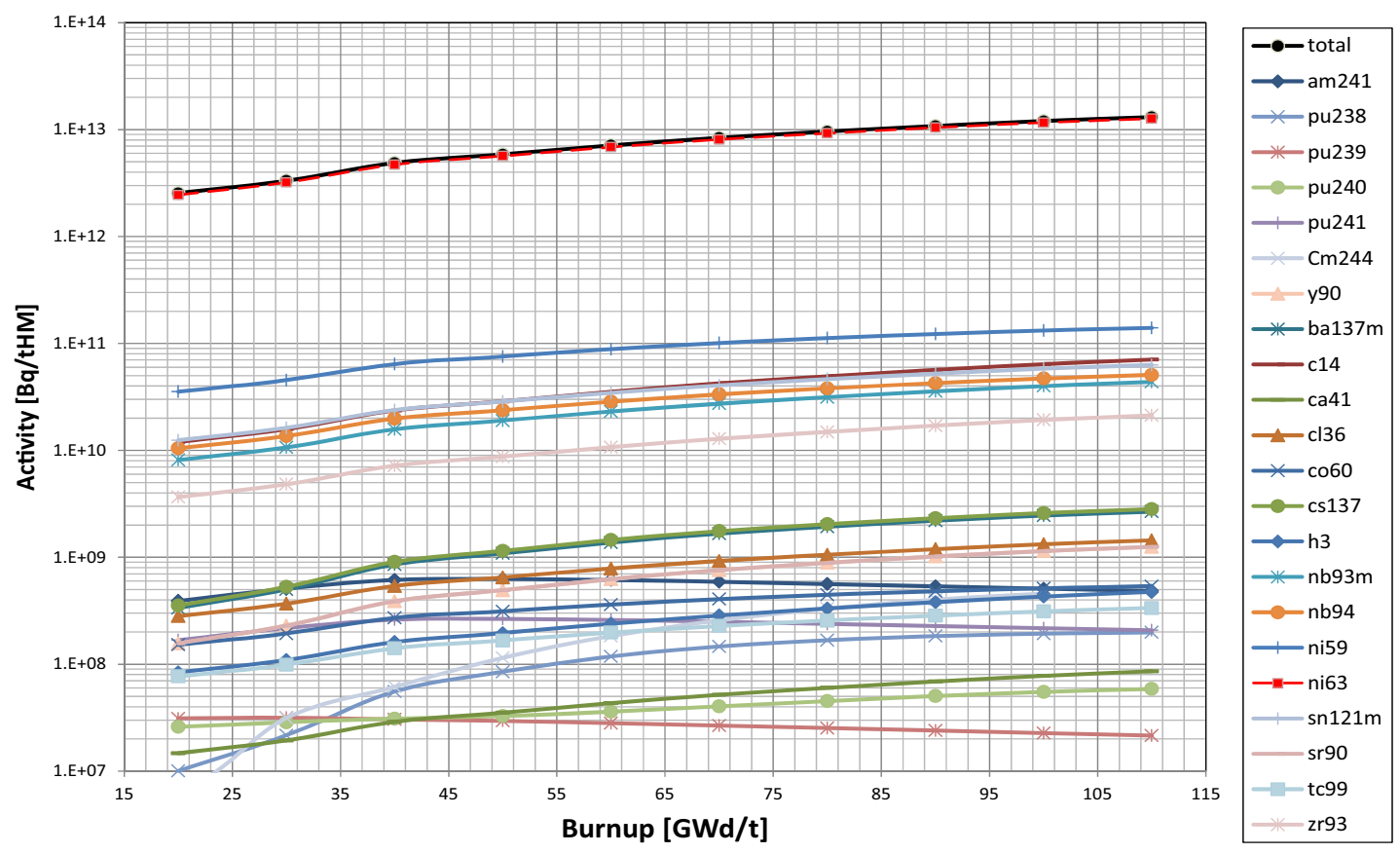

Fig. 3. Actinide, activation product and fission product activities as a function of fuel burnup, decay-corrected up to 100 years.

considered only by the TRITON calculations. Figure 2 illustrates the specific activities, per individual nuclide, and deviations between TRITON and ORIGEN-S, carried out employing different levels of irradiation data: core-follow flux $(\mathrm{CF})$ and life-average flux. The values of the deviations (continuous lines) are given on the right axis. The case represented is a $\mathrm{UO}_{2}$ PWR fuel assembly with $4.4 \%$ enrichment, $55 \mathrm{GWd} / \mathrm{t}$ burnup and cooling time of 60 days.

A sensitivity analysis aimed at investigating the relationship between burnup and induced activity in the structural material was also carried out. The build-up of isotopes as a function of burnup is illustrated graphically in Figure 3 for fission and activation products and actinides. The values refer to the case of a $\mathrm{UO}_{2}$ fuel assembly, as previously described, and were calculated using ORIGEN-S on the basis of a macro cross-section library built with TRITON (hot cladding) by depleting the fuel up to $110 \mathrm{GWd} / \mathrm{t}$ burnup (using life-averaged flux), using steps of $10 \mathrm{GWd} / \mathrm{t}$. All values reported are decay-corrected up to 100 years, in order to treat only the more long-term relevant nuclides. It can be observed that:

- the total activity build-up is a linear function with the burnup, as expected for activation products;

- the global activity is dominated by the activation of nickel, reaching $1.2 \times 10^{13} \mathrm{~Bq} / \mathrm{t}_{\mathrm{HM}}$ at $110 \mathrm{GWd} / \mathrm{t}$ (see the contribution of ${ }^{63} \mathrm{Ni}$ to the total activity in Fig. 2);

- the fission products show linear behavior for high burnup (after $40 \mathrm{GWd} / \mathrm{t}$ );

- there is a factor 5 difference from the total activity at $20 \mathrm{GWd} / \mathrm{t}$ and $110 \mathrm{GWd} / \mathrm{t}$;

- the build-up of actinides is not linear. The activity is dominated by ${ }^{241} \mathrm{Am}\left(\sim 6 \times 10^{8} \mathrm{~Bq} / \mathrm{t}_{\mathrm{HM}}\right)$ and, for very high burnup, by ${ }^{244} \mathrm{Cm}\left(<5 \times 10^{8} \mathrm{~Bq} / \mathrm{t}_{\mathrm{HM}}\right)$.

\section{Conclusions and further developments}

The objective of activation studies of Zircaloy cladding and structural material from $\mathrm{UO}_{2}$ and $\mathrm{MOX}$ spent fuel assemblies is to establish an approach that will serve as a sound basis for the assessment of all spent fuel to be disposed of in the high-level waste geological repository in Switzerland. The large heterogeneity of the fuel used in the five Swiss reactors makes this task highly complex so that different methodologies need to be investigated.

Among the different approaches discussed in this work, the author focused on the development of macro crosssection libraries customized on the Zircaloy cladding which ensure the employment of a more accurate neutron spectrum for the activation calculation. The library can be built using the SCALE/TRITON sequence and the activation analysis can be carried out with ORIGEN-S on the basis of this library. The computational time needed by SCALE/TRITON calculations is nevertheless quite long, but the time devoted to the ORIGEN-S activation calculations is extremely short. This makes the initial effort of developing the libraries worthwhile, being the use of ORIGEN not constrained by the material composition, which can be modified at will but always in agreement with the neutron spectral conditions. The axial neutron flux dependence was also taken into account by using flux weighting factors applied to the mass of the irradiated components.

A tendency to overpredict the activity by ORIGEN-S as compared to TRITON was observed, even more clearly for the MOX case (55\% more in the total activity). This is due to the dependence on the accuracy of the employed irradiation history. This dependence was investigated by 
employing irradiation data at different levels (life-averaged against core-follow), showing that the more accurate the irradiation history is, the smaller the gap is between the results. Different spectral irradiation conditions were also investigated (cold cladding against hot cladding), the cold one being 20\% lower in total activity. Furthermore, a sensitivity analysis was carried out to investigate the activity build-up as a function of the burnup at individual isotopic level. As expected, the global activity, dominated by the activation of nickel, shows a linear behavior with burnup, with the exception of the small contribution from actinides.

The study is limited to simulation of $\mathrm{UO}_{2}$ and $\mathrm{MOX}$ PWR spent fuel assemblies; a validation against measured data has not yet been performed but is still desirable. An international benchmark would be also desirable, as platform to infer the quality of these results and future works. Additional effort will be needed to include all the spent fuel types irradiated in the Swiss NPPs and foreseen for geological disposal. Particularly interesting will be the case of BWR, where a 3D model is needed to account for the neutron spectra inhomogeneity along the FA axial profile. The scope of the investigation could be even extended: the method as illustrated in this work is mainly focused on the determination of the induced activity in fuel cladding, but it could be directed to other relevant reactor components, e.g. control and safety rods and/or thimble plugs.

\section{References}

1. ORNL (Oak Ridge National Laboratory), SCALE: a comprehensive modeling and simulation suite for nuclear safety analysis and design, ORNL/TM-2005/39, vs. 6, 2011

2. I.C. Gauld, O.W. Hermann, R.M. Westfall, ORIGEN scale system module to calculate fuel depletion, actinide transmutation, fission product buildup and decay, and associated radiation terms (Oak Ridge National Laboratory, Oak Ridge, Tennessee, 2009) ORNL/TM 2005/39, Version 6, Vol. II, Sect. F7

3. NAGRA (National Cooperative for the Disposal of Radioactive Waste), Model inventory for radioactive materials, MIRAM 14. NAGRA Technical Report NTB 14-04, Wettingen, Switzerland, 2014

4. H. Maxeiner, M. Vespa, B. Volmert, M. Pantelias, S. Caruso, T. Müller, Development of the inventory for existing and future radioactive wastes in Switzerland: ISRAM \& MIRAM, ATW Int. J. Nucl. Power 58, 625 (2013)

5. NAGRA (National Cooperative for the Disposal of Radioactive Waste), Model radioactive waste inventory for reprocessing waste and spent fuel, NAGRA Technical report NTB 01-01, Wettingen, Switzerland, 2002

6. NAGRA (National Cooperative for the Disposal of Radioactive Waste), Entsorgungsprogramm 2008 der Entsorgungspflichtigen, NAGRA Technical report NTB 08-01, Wettingen, Switzerland, 2008

7. X-5 Monte Carlo Team, MCNP - A general Monte Carlo Nparticle transport code, Version 5; Vol. I: Overview and theory, Technical report LA-UR-03-1987, Los Alamos National Laboratory, 2005

8. R.A. Forrest, FISPACT-2007: User manual, Technical report, UKAEA FUS 534, EURATOM/UKAEA Fusion Association, 2007

9. W.B. Wilson et al., A manual for CINDER'90 version 07.4 codes and data, Technical report LA-UR-07-8412, Los Alamos National Laboratory, 2008

10. U. Hesse, K. Hummelsheim, GRSAKTIV-II: Ein Programmsystem zur Berechnung der Aktivierung von Brennelementund Core-Bauteilen in Vielgruppendarstellung, Technical report GRS-A-3002, Gesellschaft für Anlagen- und Reaktorsicherheit, 2001

11. A.T. Luksic, B.D. Reid, Using the ORIGEN-2 computer code for near core activation calculations, in Proceedings of the third international conference on high level radioactive waste management, ANS Las Vegas, NV (USA) 1992 (1992)

Cite this article as: Stefano Caruso, Stefano Caruso, Estimation of the radionuclide inventory in LWR spent fuel assembly structural materials for long-term safety analysis, EPJ Nuclear Sci. Technol. 2, 4 (2016) 